\title{
Medical malpractice and legal medicine
}

\author{
S. Davide Ferrara
}

Published online: 3 March 2013

(C) Springer-Verlag Berlin Heidelberg 2013

Legal Medicine and the European Medicolegal Academic Community have commenced the virtuous course of action and the difficult task of contending with Malpractice or Bad Healthcare, which have long passed the stage and the connotation of mere epidemic.

Developed in the early 1980s in North America as a result of a series of significant cultural, social, structural, and economic factors relating to post-modern Western society, the phenomenon of malpractice has definitively assumed the dimensions and the severity of a pandemic, whose transversal invasiveness does not spare nations, structures, politico-institutional regimes, social classes, professional contexts, or cultural and ideological orientations. All are united and nourished by the propellant of the claim for compensation of damage, allegedly unjust, insofar as endured for the more or less serious subjective and/or objective fault-based liability of physicians, institutions, or health professionals [1]. This concerns the fulfillment of the centuries-old path of emancipation that sees the decline of the trust of the "patient-child" in relation to the "doctorfather," once the exclusive protagonist of acts as a matter of priority driven by the principle of "first do no harm." It therefore concerns the definitive affirmation of the "patient/sick-man," the new and unique protagonist of the "confrontation-conflict" with the "physician and the institution." Both of these are technocrats, called upon to guarantee not only the means but also the results of the healthcare process: technocrats who provide healing, even at the advanced stages of illness, for virtually all diseases, and technocrats who dispense constant physical and mental well-being, guaranteeable by reason of the pluripotency of science that has become, in the social imaginary, a mediaconstructed myth of the infallibility as well as the supremacy

\footnotetext{
S. D. Ferrara $(\square)$

International Academy of Legal Medicine,

Institute of Legal Medicine, Department of Molecular Medicine,

University of Padova, Via Falloppio 50,

35121 Padova, Italy

e-mail: santodavide.ferrara@unipd.it
}

of man over nature and the dominion of reason over the mystery of life. In truth, in the current and most advanced post-genomic era of "systems biology," science is only the cognition and vehicle of probability (rather than certainty) and, often, of the limited possibility of healing or partial therapy [1]. The specialistic multi-fragmentation of knowledge and the know-how of each discipline are exhausted in the endless comparison between two kinds of truth (i.e., "reason and fact"), which belong to the current global society of risk, both environmental and behavioral, in which clinical and therapeutic medicine are an "art of scientific mimesis," which is still "art," although with a scientific foundation and increasingly technological content.

Over the last decade, the epidemic of denunciations and/or litigation, judicial and extra-judicial, for cases of presumed "malpractice or bad healthcare" has increased in an especially dramatic manner in Europe, ranging from a minimum value of double-digit percentage $(>50 \%)$ in Great Britain, the Baltic, and Eastern States, to a maximum threedigit percentage ( $>200-500 \%$ ) in Germany, Italy, the Iberian countries and the area of the Mediterranean. The sole exceptions are France and the Scandinavian countries, where the growth of the phenomenon has been reversed as a result of exemplary innovations and simplifications of procedure. According to the latest epidemiological survey of the European Community - the Special Eurobarometer on Medical Errors in 2006 - approximately $80 \%$ of EU citizens perceive medical errors as a major issue and about $50 \%$ believe they will be personally involved in a case of medical malpractice [2]. This statistical analysis shows that public opinion has become aware of the fact that there are ways to pursue claims for compensation against healthcare professionals and institutions that are not predestined to fail.

The percentage of acceptance for compensatory claims between 2005 and 2010 reached its peak in Sweden and Denmark (40\%), being smaller in Central and Southern Europe, with an average settlement of around $€ 30,000$ per case in all of the EU countries. The exponential growth of the phenomenon has been accompanied by a proportional 
increase in the cost of the coverage of claims, estimated to be in excess of $200 \%$ by the European Hospital and Healthcare Federation (HOPE) Standing Committee. These costs, distributed across the population, fluctuate between 9 and 15 euros per capita, with the highest figures recorded in Britain [2].

Increases in the cost of coverage involve increasing difficulty in procuring insurance companies, especially for the most high-risk surgical disciplines (gynecology, orthopedics, etc.), as well as for the largest hospitals, at times forced to resort to self-protection by budgetary adjustments, which are certainly not conducive to the ameliorative development of the quality and plurality of health services on offer. Faced with this dramatic evolution, the European Union has thus far remained virtually inert, both on the legislative plane and that of proposals of operative systems, aimed at developing knowledge and solving the problems posed. Since 1997, the year in which the "Convention on the dignity of human beings and biomedicine" was adopted (also called the "Oviedo Convention"), which in article 4 provides that the "patient has a fundamental right to obtain compensation for unjustified damage (harm) suffered as a result of a medical intervention," and in article 24 provides that any "intervention in the healthcare sector should be carried out in compliance with norms and professional obligations," there has not been any normative action intended to harmonize the regulations regarding medical professional liability in Europe. In May 2008, the Council of Europe organized a conference aimed at identifying good practice in medical liability in the 47 Member States, alternative methods for resolving disputes, as well as the redefinition of the role of the public and private sectors in financing compensation. The conference highlighted: (1) benefits, with the advantage of speed and cost-effectiveness for both patients and practitioners, in European Countries in which alternatives to ordinary court-based channels had been introduced; (2) necessities of taking steps in order to strengthen trust between healthcare professionals and patients, in particular with regard to new patient-safety policies, European training program in healthcare, and in appropriate ethical rules for professionals and responsible stakeholders. Unfortunately, this useful moment for comparison and exchange, as well as for a statement of principles with a harmonizing value, was not followed by concrete initiatives with practical implications. Dedicated Reporting Systems, capable of monitoring the phenomenon, are still lacking at the European level and at the level of individual nations. There are also no EU regulations, guidelines, and recommendations to prevent, or at least reduce, the multiplicity of regulatory frameworks and national operative systems. Today, one sees the coexistence of systems anchored in the common law juridical models or, more directly, traceable to Roman law, such as, respectively, the Nordic countries and Great Britain, the Mediterranean countries, and Central and Eastern Europe, where there exist dissimilar legislative-juridical models, from which arise diverse operating systems of dispute resolution, on a judicial, criminal, civil and/or administrative, or, mostly, extra-judicial basis.

As has often happened in other scientific and disciplinary contexts, the medicolegal community has provided the first example by: (a) respecting the Hippocratic oath of the third millennium, of knowledge, know-how and again the "search for the truth," through the identification and self-report to the medical community of errors committed during the performance of one's work and assistance; (b) posing an initial remedy to the heterogeneous detriment of the patient's rights, through the triggering of a positive process aimed at "European consensus on ascertainment methodology and criteria for evaluating damage from medical malpractice," on living and deceased persons.

To the above-mentioned ends, the writer, in his capacity as temporary President-Representative of the European Academy of Legal Medicine (EALM) in the years 20092012, promoted and chaired an EALM Working Group of Experts who have contributed to the realization of a monograph [3] and European Guidelines, the result of a Consensus Conference that took place in Rome in 2011. This is the final outcome of a 3-year evolutionary process of an EALM scientific project, created on the basis of a specific and coherent rationale [1], aimed at acquiring knowledge of the "state of the art" of the European medicolegal scientific culture and directed towards the harmonization of the scientific research, skills and professional practice of the European bio-medicolegal sciences. With the prospect, now actually forthcoming, of a recording in the Official Journal of the European Union of the specialization of "Legal and Forensic Medicine," for the time being already recognized in October 2012 by the European Union of Medical Specialists, such as the "Thematic Federation" of interdisciplinary interest, due to the efforts and merit of the European Council of Legal Medicine.

The state of the art, acquired on the subject of professional practice [4] and associated guidelines of ascertainment and evaluation, as well as of scientific research [5], of innovatory productive capability [6], and of the role of impact of disciplinary journals [7], has permitted the identification of those areas in need of present and future coordinated intervention to be realized by the European Academy, European Council and International Academy of Legal Medicine, in a joint effort to increase the development and visibility of the discipline. This process finds clear expression in the publication of the monograph [3] and of European guidelines [8] on Malpractice and Medical Liability, respectively by Springer and the International Journal of Legal Medicine, which launches in this issue a new section dedicated to Guidelines and Protocols of medicolegal significance, produced as a priority by the International 
Academy of Legal Medicine, the European Academy of Legal Medicine, the European Council of Legal Medicine, as well as related Societies, Academies and Associations of Bio-Medicolegal Sciences.

\section{References}

1. Ferrara SD, Pfeiffer H (2010) Unitariness, evidence and quality in bio-medicolegal sciences. Int J Legal Med 124:343-344

2. Eurobarometer Series (2006) Special 241/64.1 and 64.3 TNS: Opinion and Social. European Commission Medical Errors. Accessed 20 December 2012

3. Ferrara SD, Boscolo Berto R, Viel G (eds) (2013) Malpractice and medical liability_European state of the art and Guidelines. Springer, Berlin
4. Ferrara SD, Bajanowski T, Cecchi R, Snenghi R, Case C, Viel G (2010) Bio-medicolegal guidelines and protocols: survey and future perspectives in Europe. Int J Legal Med 124:345-350

5. Ferrara SD, Bajanowski T, Cecchi R, Boscolo-Berto R, Viel G (2011) Bio-medicolegal scientific research in Europe: a comprehensive bibliometric overview. Int J Legal Med 125:393402

6. Viel G, Boscolo-Berto R, Cecchi R, Bajanowski T, Vieira ND, Ferrara SD (2011) Bio-medicolegal scientific research in Europe. A country-based analysis. Int J Legal Med 125:717-725

7. Boscolo-Berto R, Viel G, Cecchi R, Terranova C, Vogliardi S, Bajanowski T, Ferrara SD (2012) Journals publishing biomedicolegal research in Europe. Int J Legal Med 126:129-137

8. Ferrara SD, Baccino E, Bajanowski T, Boscolo-Berto R, Castellano M, De Angel R, Pauliukevičius A, Ricci P, Vanezis P, Vieira DN, Viel G, Villanueva E, The EALM Working Group on Medical Malpractice (2013) Malpractice and medical liability. European Guidelines on Methods of Ascertainment and Criteria of Evaluation. Int J Legal Med (in press) (DOJ) 